\section{Oral health campaign returns}

Philips Oral Healthcare is a sponsor of National Smile Month and is reactivating is \#habits4life campaign for 2020 due to its success last year.

This campaign aims to drive the importance and education around three key oral care habits and create \#habits4life, so on a daily basis people can take control of their own oral health with the ultimate aim of living healthier lives.

The three pillars of the campaign are:

1. Visit your dentist - visiting your dentist regularly helps prevent wider issues for both your oral health and ultimately systemic health

\section{A checklist for getting back on track}

As dental practices start to reopen, this is going to be a very critical time for you, your practice, your team and of course, your patients. So it's vital that you identify the strategies to allow your business to bounce back and recover profits lost during lockdown.

To help you with this, Henry Schein have produced a bounce back checklist with suggestions and ideas for how you can do this - including:

- How to ensure your practice is ready to reopen

- What the new normal might look like

- How to manage your diary and prioritise your appointments

- How to look after the health of your business

- Contactless arrivals and departures

- How to run virtual consultations

- Helpful marketing ideas

- How to lead your team

- How to communicate effectively with your patients

- A YouTube playlist to help you recommission your equipment.

There are many other ideas to help you prepare for what will become the new 'normal' in the world of dentistry. And it's going to be quite different from how it was before.

To find out more visit https://issuu. com/henryscheinuk/docs/hsd162-04-20_ planning_your_business_bounceback fin?fr=sMzViZjExMDc5Mjc.
2. Brush your teeth with an electric toothbrush and floss - taking good care of your oral hygiene ensures a healthier mouth and body

3. Healthy nutrition (reducing sugar reduces obesity/diabetes risk) and introducing 'Sugar Swaps' is recommended as a healthy diet leads to a healthier life.

Dr Ben Atkins, President of the Oral Health Foundation, said: 'Philips' three pillars dovetail with those of the Oral Health Foundation. I applaud the preventive ethos the company is recommending - that developing habits for life is vital if patients are going to achieve both a reduction in levels of decay and periodontal disease. If this also achieves improved knowledge about the systemic risks associated with poor oral health - so much the better.

'I am working with Philips on a campaign to drive behavioural change in patients as part of a prevent approach which I believe is not only much more ethical and responsible, but is a far more sustainable model for the profession.'

For more information about Philips Sonicare and AirFloss tools in the dental professional's armoury to tackle or prevent decay and periodontal disease, visit www.philips.co.uk/ dentalprofessional.

\title{
A reliable referral centre for advanced implant rehabilitation
}

Do you need to refer a patient for simple or complex dental implant treatment? Consider the Centre for Oral-Maxillofacial and Dental Implant Reconstruction in Manchester, led by renowned educator and Specialist Oral Surgeon, Professor Cemal Ucer.

With a highly skilled team and cutting-edge facilities of the Manchester Postgraduate Dental Institute and ICE Hospital, the Centre's referral services include:

- Maxillary sinus grafting and preprosthetic surgery

- Day-care or in-patient treatment at a private hospital

- GA or IV sedation provided by a team of consultant anaesthetists and medical staff

- 3D customised allograft block bone grafting
- Vertical GBR, with or without simultaneous implant placement

- Autologous PRF/PRP growth factor therapy

- Nerve lateralisation or repositioning

- Zygomatic and maxillofacial dental implant reconstructions at Manchester ZAGA Centre

- Management of failing dental implants/ sinus grafts/nerve damage/peri-implant diseases

- 3D printed, customised, subperiosteal implants for severely atrophic cases.

For a reliable implant referral partner, contact the Centre for Oral-Maxillofacial and Dental Implant Reconstruction.

Secretary: Mel Hay Email: mel@mdic.co or Tel: 01612371842.

For more information on the implant training available from Ucer Education, visit www.ucer.education or call 01612371842.

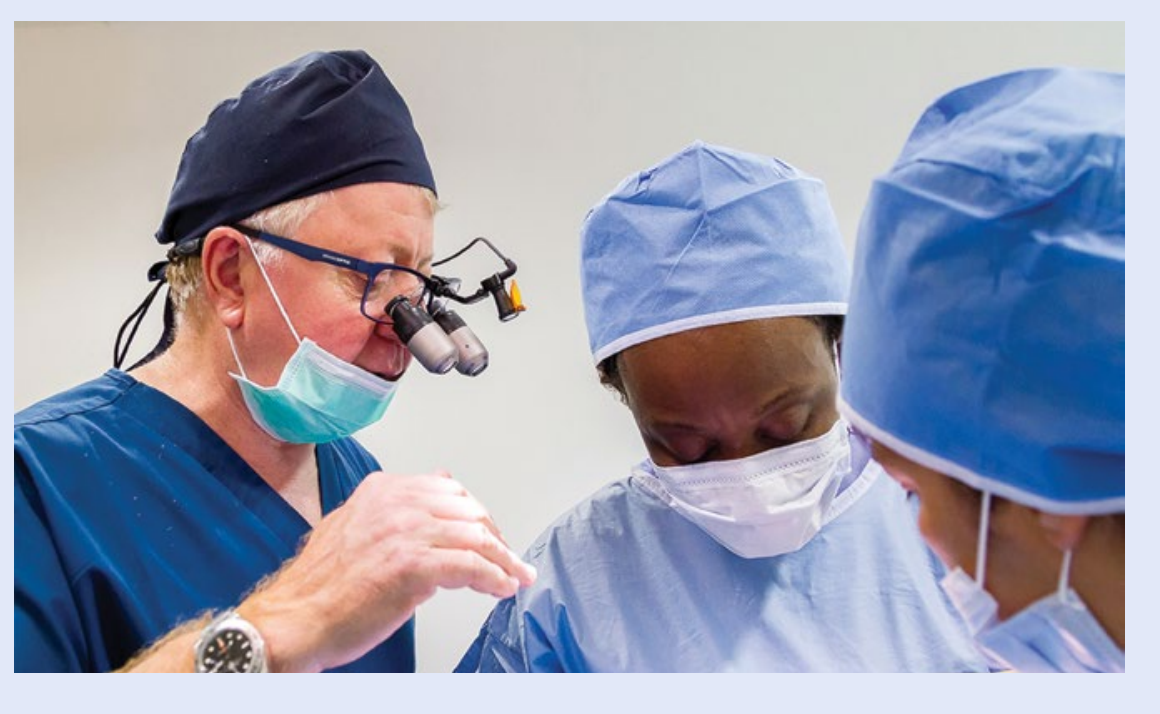

